\title{
ENHANCEMENT OF EMBRYONIC AND HATCHING PERFORMANCE OF RHODE-ISLAND RED CHICKEN BY EXPOSING INCUBATED EGGS TO LIGHT PULSES IN RELATION TO THEIR SHELL PIGMENTATION
}

\author{
M. F. A. Farghly ${ }^{1}$,O. H. El-Garhy ${ }^{2}$ and M.G. Abdelfattah ${ }^{1}$ \\ 1-Poultry Production Department, Faculty of Agriculture University of Assiut (71516), Egypt, \\ 2- Animal 2Production Department, Faculty of Agriculture, Benha University, Egypt \\ Corresponding author: farghly20002000@yahoo.com farghly20002000@aun.edu.eg
}

Received: 28/9/2017

\section{SUMMARY}

Light pulses (PS) could be an effective tool to decontaminate and improve the hatching of incubated eggs. So, this study assessed the role of PS during incubation in improving embryonic development and hatching performance of Rhode Island Red chicken in relation to eggshell pigment. A total of 900 eggs were randomly divided into three groups according to their eggshell pigmentation (light, medium and heavy) and incubated with or without being exposed to PS. The exposure to PS significantly $(p<0.05)$ increased the final embryo weight, egg weight loss, chick's weight at day 7 post-hatch, relative weights of chick internal organs (breast, liver and ovary) and decreased hatching time. However, no significant differences were observed in hatchability, chick characteristics, hatch chick weight, chick weight loss and residual yolk sac. Regarding eggshell pigments, there was a positive relationship between chick length, relative weight of liver and chick quality with the density of eggshell pigments. However, there were no differences recorded among different egg shell pigmentation groups in embryo weight percentages, hatchability, egg weight loss, culled chicks, hatch time, body temp., chick sex, weight gains of chick and percentages of most internal organs. There were significant differences in most studied traits (percentages of embryo weight, hatching performance, chick quality, chick weight loss, relative weight gain, chick breast and liver), due to the interaction effects of pulses with eggshell pigment. It could be concluded that the medium to heavily pigmented eggs exposed to PS during incubation showed favourable results of hatchability and hatch time. Therefore, the application of pulses could be successful in hatchery with no negative effect on chick's quality.

Keywords: Light pulses, shell pigmentation, embryonic and hatch performance, Rhode Island chicken.

\section{INTRODUCTION}

In artificial incubation, two basic factors play main roles in embryonic development and are carefully controlled: high fertile eggs and maintaining suitable or optimal environmental conditions of incubation (Abiola et al., 2008 and Portugal et al., 2014). Researchers are searching for modifications in incubation conditions such as light, laser, ultrasonic and magnetic waves as environmental stimuli for embryonic development and hatchability, thereby increasing productivity (Shafey et al., 2005, Archer et al., 2009, Zhang et al., 2012, Farghly and Mahrose 2012, Yu et al., 2014, Pandian et al., 2015, Farghly et al., 2015, Farghly and Ghonime 2016 and Farghly et al., 2017ab). Avian embryos can respond to lighting stimulation by melatonin produced from pineal gland (Faluhelyi and Csernus, 2007 and Archer and Mench, 2014). However, continuous light during incubation could have side effects since heat caused by incandescent bulbs can lead to decreased hatchability (Özkanet al., $2012 \mathrm{ab}$ ). Laser and other high energy sources of light such as intense pulsed light is becoming widely used in eliminating microbial contamination from the surface of shell eggs (Lasagabaster et al., 2011) and help in tissue development during embryogenesis (Avila et al., 2009). They are also used to activate cell division, collagenous and elastic fibres formation, blood vessels regeneration, bone tissue cicatrisation and reepithelization of destroyed tissues (Town, et al., 2007). Besides, exposure to pulsed light is associated with photoreaction of egg components, including lipids, antioxidants, flavour compounds and pigments (Manzocco et al., 2014). Studies showed that light pulse stimulates embryonic growth and hatchability performance (Farghly, 2012 and 2015).

Incubation discrepancies may occur by light spectral characteristics that reaches the embryos. Eggshell of same breed can have different levels of eggshell pigmentation. Photo stimulation effects on embryonic performance depends on light amount that reaches the embryos (Ghatpande et al., 1994). The light spectral transmission into egg is affected by intensity of eggshell pigments and thickness (Shafey et al., 2004\&2005). Under light conditions, embryo development of eggs with pigmented shells is slower than with un-pigmented shells, and depigmentation of eggshells results in early hatching. In addition, egg shell colour and quality, may affect embryonic and hatching performance (Copur, et al., 2010, Farghly et al., 2015 and Farghly and Shabaan,2016).

A number of light techniques such as light pulses have recently been used to improve hatching performance either through direct contact with the 
embryo or that non-direct effect on internal egg components, especially when exposed to light pulses that would show more embryonic development, less cost and avoid undesirable effects of continuous light (Farghly, 2012 and 2015). Unfortunately, little information areavailable on factors that cause changes in response to light pulses during incubation. Effect of eggshell pigment level on embryonic growth and egg hatchability under light pulses is poorly understood. Thus, the this study aimed to investigate if light pulses could be a successful tool improves the development of embryos and hatch performance of eggs in Rhode Island Red chicken and relationship to egg-shell pigmentations.

\section{MATERIALS AND METHODS}

The present study was carried out in the Poultry Farm, Poultry Production Department, Faculty of Agriculture, Assiut University, Assiut, Egypt. A total number of 900 eggs were divided into three groups according to the concentration of their eggshell pigment (light, medium and heavy). Each group $(n=300)$ was subdivided into two subgroups $(n=150)$ and placed in one of two identical incubators. The eggs placed in the first incubator were exposed to light pulses (20 pulses /minute defined as flashing light with light intensity of 100 to150 lux); Eggs in second incubator were incubated under dark conditions. The effect of light pulses in relation to eggshell pigment on embryonic development and hatchability performance was studied in a $3 \times 2$ factorial arrangement of treatments. The setters were operated at $37.8^{\circ} \mathrm{C}$ temperature and a relative humidity of $55 \%$ for the first 18 days of incubation. All eggs were transferred to a hatcher (last 3 days of incubation) operated at $37.3^{\circ} \mathrm{C}$ and $65 \%$ relative humidity.

Eggs were weighed before being set (setting egg weight) and after 18 days of incubation to determine the percentage of loss in egg weight. Initial start time of incubation was recorded after eggs had been set and the incubator was turned on to obtain the exact hatch time and this was considered as incubation zero time. For embryonic development, 5 eggs (normal embryos) were taken randomly from each treatment after 7, 14 and 21 days of setting and then examined. Chick length was measured with the chick's dorsal surface extended over a ruler from the beak to the middle toe. At hatching, normally and abnormally hatched chicks were counted to estimate the culled chicks and hatchability percentages. Hatchability = (hatched chicks/fertile eggs) x100. Hatch time and chick weight was recorded every eight hrs after the 1st chick was hatched. Hatched chicks were removed, wing-banded, weighed and recorded as chick weight at hatch, then placed again in the hatchery after record the hatch time. Chick weight loss percent was estimated as follow: chick weight loss $\%=(($ chick weight at hatch - chick weight at pull out)/chick weight at hatch)x 100 . Chicks were examined for quality traits such as appearance, eyes, activity, aspect of navel area and legs conformation.
Chick quality scores were given according to Deeming (1995) using a scale from 1 (poor quality) to 5 (good quality). After measuring chick BW, length, and quality, five chicks from each group were humanely killed and harvested to measure residual yolk weight. Weight of residual yolk was subtracted from BW to estimate yolk-free body mass. Body temperature values of hatched chicks were measured with a digital thermometer. The same baby chicks were used to calculate the weight of breast, legs, liver, heart, ovary, testis and yolk sac. The chick sex was also determined by examining the internal ovary or testis at the intervals of hatched chick's age $1^{\text {st }}, 2^{\text {nd }}$, $3^{\text {rd }}$ and $7^{\text {th }}$ day of age.

Data were statistically analysed using the ANOVA and the general linear model (GLM) procedure by the SAS (SAS Institute, version 9.2, 2009) software. Differences between treatments means were tested for significance by the Duncan's multiple ranges (DMR) test (Duncan 1955). Percentages of all studied traits in the experiment were transformed to values of Arcsin. All data were analyzed using factorial design according to the following model:

$\mathbf{Y}_{\mathrm{ijkl}}=\mu+\boldsymbol{\alpha l}+\mathbf{G}_{\mathrm{i}}+\mathbf{M}_{\mathrm{j}}+(\mathbf{G x M})_{\mathrm{ij}}+\mathbf{E}_{\mathrm{ijl}}$

Where: $\mathrm{Y}_{\mathrm{ijkl}}=$ observation; $\mu=$ overall mean; $\alpha \mathrm{l}=$ replicates effect; $G_{i}=$ light pulses effect $(i=1-2)$; $\mathrm{M}_{\mathrm{j}}=$ eggshell pigmentation effect $(\mathrm{j}=1-3) ;(\mathrm{GxM})_{\mathrm{ij}}=$ light pulses $\mathrm{x}$ eggshell pigmentations interaction; and $\mathrm{E}_{\mathrm{ijkl}}=$ experimental error.

\section{RESULTS AND DISCUSSIONS}

\section{Embryonic developments:}

The results of embryonic weights (\%) are shown in (Table 1). Insignificant differences were observed at all embryonic ages between eggshell pigmentation levels. Regarding the incubated eggs exposed to light pulses (PS), embryos showed higher values in weight $(\mathrm{P} \leq 0.05)$ than those incubated under darkness $(\mathrm{D})$ at the $3^{\text {rd }}$ week of embryogenesis. However, D and PS groups had similar weight values at the $1^{\text {st }}$ week and the $2^{\text {nd }}$ week of embryogenesis. Significant interactions of eggs exposed to pulsedlight coupled with egg shell pigmentation groups had higher values in embryo weight percentages at $3^{\text {rd }}$ week of embryogenesis. Averages of embryo percentages increased when medium and heavy pigmented eggshell groups were incubated under pulsed light than light pigmented eggshell group. Light has an important effect in the embryonic growth and may be related to the developmental stage of the extra embryonic membrane (Shanawany, 1990). It may be that the effect of pulsed light stimuli lasts long enough to increase satellite cell proliferation and tissue changes in the chick embryo, resulting in accelerated embryo development (Avila et al., 2009; Rozenboim et al., 2004; Shafey, et al., 2004 and Shafey et al., 2007). Rozenboim et al. (2004) and Khalil (2009) reported that incubating eggs exposed to light enhanced protein synthesis and attributed these to improvements in metabolic responses to light via activating the thyroid and increasing biochemical 
constituents in embryos blood (Rozenboim et al., 2004; Khalil, 2009). Faluhelyi and Csernus, (2007) and Ozkan et al. (2012a) found that acceleration of embryos growth may be controlled by rhythmic melatonin during last incubation period. This hormone also has powerful antioxidant properties which can be relevant because embryos are high sensitive to oxidative stress. Yu et al. (2014) reported that light may be promoter to maturate the expression of mRNA in the small intestines of late-stage birds embryos. The findings of the current work are in agreement with those of Rozenboim et al. (2004),
Abd El-Azim et al. (2005), Farghly and Mahrose (2012), Ozkan et al. (2012a), Zhanget al. (2012), Archer (2015) and Farghly et al. (2015\&2017ab) who found that incubating eggs subjected to light produced heavier embryos. Farghly (2012) and Farghly, (2015) reported that the highest value of embryo weight was observed in incubated eggs exposed to pulsed light. On the other hand, Fairchild and Christensen (2000) and Pandian et al. (2015) observed that light had no effect on increasing embryo weight during incubation.

Table 1. Embryo development as affected by light pulses and shell pigmentation

\begin{tabular}{|c|c|c|c|c|}
\hline \multirow{2}{*}{\multicolumn{2}{|c|}{ Treatments }} & \multicolumn{3}{|c|}{ Embryonic weights (\%) } \\
\hline & & $1^{\text {st }}$ week & $2^{\text {nd }}$ week & $3^{\text {rd }}$ week \\
\hline \multirow{5}{*}{ Egg shell pigmentation } & $\mathbf{L P}$ & 4.12 & 22.14 & 62.54 \\
\hline & MP & 4.18 & 22.53 & 63.00 \\
\hline & HP & 4.29 & 23.19 & 63.32 \\
\hline & $\mathrm{SE}$ & 0.320 & 1.30 & 1.22 \\
\hline & $\mathrm{P}$ value & 0.5059 & 0.2052 & 0.3659 \\
\hline \multirow{4}{*}{ Lighting conditions } & D & 4.12 & 22.32 & $62.36^{b}$ \\
\hline & PS & 4.27 & 22.92 & $63.54^{\mathrm{a}}$ \\
\hline & $\mathrm{SE}$ & 0.31 & 1.32 & 1.08 \\
\hline & $\mathrm{P}$ value & 0.1947 & 0.2238 & 0.0060 \\
\hline \multirow{8}{*}{$\begin{array}{c}\text { Pigmentation X Lighting } \\
\text { interactions }\end{array}$} & LP X D & 4.06 & 22.10 & $62.18^{b}$ \\
\hline & MP X D & 4.05 & 21.72 & $62.03^{b}$ \\
\hline & HP X D & 4.26 & 23.15 & $62.88^{a b}$ \\
\hline & LP XPS & 4.18 & 22.17 & $62.89^{a b}$ \\
\hline & MPXPS & 4.32 & 23.35 & $63.98^{\mathrm{a}}$ \\
\hline & HP XPS & 4.32 & 23.24 & $63.76^{\mathrm{a}}$ \\
\hline & $\mathrm{SE}$ & 0.33 & 1.27 & 1.06 \\
\hline & $\mathrm{P}$ value & 0.6174 & 0.2175 & 0.0424 \\
\hline
\end{tabular}

Superscripts $^{\mathrm{a} a \mathrm{and}}$ in a row mean that the common $(\mathrm{P} \leq 0.05)$ is significantly different.

Pigmentation level: Low (LP), Medium (MP), Heavy (HP). Lighting conditions: Dark (D), Light pulses (PS)

Light acceleration of embryos growth controlled by the amount and period of light exposure that reaches the embryo and then the amount of $\mathrm{Ca}$ form eggshell (Khalil, 2009). Eggshells with differences spectral characteristics may affect photostimulation through incubation period. Intensity of protoporphyrin pigment of brown eggshells can alter spectral characteristics of transmitted light into egg depending on its selective absorbing and passing of certain illumination wavelengths with reflecting of others (Clifford and Philpott, 2002). High light intensity may have negative effects due to increase the light amount that crosses the eggshell and then reaches the embryo and that in related to darker pigment of egg (Ghatpande et al., 1994). Embryonic growth of the pigmented eggs was slower than that of the unpigmented eggs depending on incubated light as reported by Farghly et al. (2015) who found that embryos from white eggs incubated under light were the best, followed by brown eggs incubated under dark conditions. Also, Shafeyet al. (2002 and 2004) found that the level of brown pigment influences light transmission through the eggshell. However, Shafey et al. (2005) reported that intensity of brown pigment had insignificant effect on embryo growth.
$\mathrm{Yu}$ et al. (2016) found that low pigmentation concentration resulted higher light transmission.

\section{Hatchability:}

Data in Table (2) show that eggshell pigmentation did not affect hatchability, egg weight loss and hatching time. In light pulse treatments, eggs exposed to pulsed light had lower values $(\mathrm{P} \leq 0.05)$ of hatching time. While, eggs exposed to pulsed light had higher percentages $(\mathrm{P} \leq 0.05)$ of egg weight loss, this indicates that pulsed light are more effective during the late incubation period. Insignificant differences $(\mathrm{P}>0.05)$ were found in hatchability percentage. There were interactions $(\mathrm{P} \leq 0.05)$ between eggshell pigment and light pulses on hatchability, egg weight loss and hatch time. Medium eggshell pigmentation and pulsed light interaction had the highest effect. Abd El-Azim et al. (2005) and Farghly et al. (2015\&2017ab) reported that incubated light enhanced hatchability percentage. Incubation conditions of eggs influenced the metabolism or heat production and embryos growth and then hatchability percentage and incubation period (Shafey et al., 2007). Using flash bulbs did not excess incubator heat and decrease the cost of electricity. Shafey et al. (2004) observed that type and amount of light 
passing the embryo could affect hatchability. Shafey et al., (2002), Archer and Mench (2014) and Farghly (2012 and 2015) found that incubating light and light pulses improved hatchability traits of chicken and quail eggs. Khalil (2009) indicated that these improvements were related to physiological and metabolic response to light during embryonic development. In contrast, Shanawany (1990) and
Archer and Mench (2014) reported insignificant differences in hatchability of eggs incubated under dark or lighted conditions. Ozkan et al. (2012a) and Zhang et al. (2012) reported that incubated light had no effect on hatchability or embryo mortality (Özkan et al., 2012b and Zhang et al., 2012).

Table 2. Hatching performance as affected by light pulses and shell pigmentation

\begin{tabular}{|c|c|c|c|c|}
\hline \multirow[t]{2}{*}{ Treatments } & & \multicolumn{3}{|c|}{ Hatching performance traits } \\
\hline & & Hatch (\%) & $\begin{array}{c}\text { Egg weight loss } \\
(\%)\end{array}$ & Hatch time (hrs) \\
\hline \multirow{5}{*}{ Egg shell pigmentation } & LP & 84.50 & 12.92 & 499.55 \\
\hline & MP & 86.98 & 12.88 & 498.66 \\
\hline & HP & 86.27 & 12.32 & 497.84 \\
\hline & SE & 2.21 & 0.73 & 2.86 \\
\hline & $P$ value & 0.1683 & 0.3089 & 0.5977 \\
\hline \multirow{4}{*}{ Lighting conditions } & $\mathrm{D}$ & 85.12 & $12.32^{b}$ & $500.52^{\mathrm{a}}$ \\
\hline & PS & 86.71 & $13.08^{\mathrm{a}}$ & $496.85^{b}$ \\
\hline & SE & 2.25 & 0.65 & 2.10 \\
\hline & $P$ value & 0.1544 & 0.0240 & 0.0019 \\
\hline \multirow{8}{*}{$\begin{array}{c}\text { Pigmentation X Lighting } \\
\text { interactions }\end{array}$} & LP X D & $84.33^{\mathrm{b}}$ & $12.64^{\mathrm{ab}}$ & $501.28^{\mathrm{a}}$ \\
\hline & MP X D & $85.07^{\mathrm{b}}$ & $12.32^{\mathrm{ab}}$ & $501.12^{\mathrm{a}}$ \\
\hline & HP X D & $85.97^{\mathrm{ab}}$ & $12.01^{\mathrm{b}}$ & $499.15^{\mathrm{ab}}$ \\
\hline & LP XPS & $84.67^{\mathrm{b}}$ & $13.19^{\mathrm{ab}}$ & $497.81^{\mathrm{ab}}$ \\
\hline & MPXPS & $88.90^{\mathrm{a}}$ & $13.43^{\mathrm{a}}$ & $496.19^{b}$ \\
\hline & HP XPS & $86.57^{\mathrm{ab}}$ & $12.63^{\mathrm{ab}}$ & $496.53^{b}$ \\
\hline & SE & 1.72 & 0.65 & 2.19 \\
\hline & $P$ value & 0.0367 & 0.0505 & 0.0529 \\
\hline
\end{tabular}

Superscripts $^{\mathrm{a} a n d \mathrm{~b}}$ in a row mean that the common $(\mathrm{P} \leq 0.05)$ is significantly different.

Pigmentation level: Low (LP), Medium (MP), Heavy (HP). Lighting conditions: Dark (D), Light pulses (PS)

The acceleration in hatch time due to pulsed light has been credited in general as a stimulated embryonic development rate. Abd El-Azim et al. (2005), Farghly et al. (2015) found that exposed fertile eggs to light resulted in early hatching time compared with incubated in darkness (Farghly et al., 2015\& 2017ab). Fairchild and Christensen (2000) and Abd El-Azim et al. (2005) found that illumination during incubation period had no affect hatch performance of turkeys. Farghly (2012) found that pulsed light had insignificant affect hatching time of incubated quail eggs. Rozenboim et al. (2004), Ozkan et al. (2012a) and Zhang et al. (2012) reported that incubated photo stimulation had no effect on hatching period. Abd El-Azim, et al. (2005) and Farghly (2012 and 2015) found no difference in egg weight loss during incubation under lighted or dark conditions. However, Farghly et al. (2015\&2017b) found that incubating egg under light conditions significantly increased egg weight loss values.

Regarding pigmentation levels and pulsed light interaction, medium pigmented eggs under light pulses had the highly hatchability percentage. These findings are similar with Shafey et al. (2005), Yang et al. (2009) and Kumar et al. (2012) who observed lower hatchability percentages in light shell pigmentations of eggs. Farghly et al. (2015) and
Farghly and Shabaan (2016) found that brown spotted eggs showed higher hatchability percentages (even when incubated under dark or light conditions) followed by those of spotted violet and white eggs. Also, they reported that egg weight loss increased to the highest level in brown eggs incubated under light, followed by brown eggs incubated in darkness, followed by violet eggs incubated in darkness. Egg shell coloration could indicate a need for more relative humidity (Deeming, 2011). Most probable cause of lower hatchability in pigmented eggs might be due to higher loss in moisture content and then less specific gravity, which result in low hatchability. Another reason is a positive association of the density of pigment with hatchability, apart from thicker shell with more calcium and high specific gravity of brown shelled eggs. Light brown eggs may be a sign of prematurely laid eggs caused by some type of environmental stress (Chukwuka et al., 2011). Shafey et al. (2005) found that egg weight loss percent was not affected by level or intensity of brown egg pigments during incubation period.

\section{Chick's sex and quality:}

Results shown in Table(3) showed significant differences in chick lengthand quality as affected by egg shell pigmentation, while insignificant differences existed in chick sex, culled chick's value and body temperature. Each chick sex, length, 
quality, culled chick's valuesand body temperature values were not affected by pulsed light. Heavy egg shell pigmentation exposed to light pulses had the highest value of chick quality. Improved quality of a flock at slaughter age can be realized with highquality day-old chicks as starting day old chicks. One day-old chick quality score can be related to many factors, including all egg characteristics with incubation conditions (Deeming, 1995). Chicks produced from egg incubated light conditions, performed to be more active compared with those produced from egg incubated in darkness. There is also evidence that biological rhythms associated with body temperature regulation are established prehatching (Hill et al., 2004). These rhythms depending on the melatonin rhythms that secrete in the embryo (Csernus et al., 2007; Faluhelyi and Csernus, 2007). Intermittent lighting (15 $\mathrm{min}$ on and $15 \mathrm{~min}$ off) in which the rise in egg temperature does not exceed $0.11^{\circ} \mathrm{C}$ eliminates the heat effect. Appling a lighting fixtures that do not enhance the excess heat in the incubator eliminates the risk of low hatch performance. Shafey et al. (2007) reported that incubation conditions affected embryonic metabolism or heat production and then chick quality. Farghly (2012) and Farghly (2015) reported that pulsed light had no significant effect on chick quality in Japanese quail. Archer and Mench (2014) reported that providing broiler eggs with $12 \mathrm{hrs}$ of incubated light decrease their tolerance stress as indicated by physical asymmetry, corticosterone, and antibody production. They concluded that chick quality improved by lighted incubation. Light pulses had significantly no effect on chick sex. Yu et al. (2014) reported that light may promote hormones related to sex determination through certain protein synthesis. Farghly (2015) and Farghly et al. (2017a) found that incubating light affected culled chick's values, body temperature and chick sex values. Farghly and Sharaqa (2016) reported that incubating light treatment increased body temperature, but insignificant effect on culled chick and chick sex. Shafey et al. (2007) found that incubation conditions affect chick growth and lengths. Farghly (2015) reported no significant defences in chick lengths. The current study shows that the levels of pigmentation in brown eggshells affect chick length and quality, but no in hatch chick weight. Archer (2015) found that brown eggs incubated under lighting measured the proportion of non-defect chicks compared with incubation in the dark, and that white eggs show the same trend as red eggs. The same researcher found that incubatedlight or pigment level had no effect on chick length. Changes in the physical dimensions of eggs and in eggshell pigmentation were reported to have altered the light type and amount passing through eggshell and then reaching or passing the embryos and thus affect chick lengths and quality traits (Shafey et al., $2002 \&$ 2004).

Table 3. Chick sex and quality as affected by light pulses and shell pigmentation

\begin{tabular}{|c|c|c|c|c|c|c|}
\hline \multirow{2}{*}{ Treatments } & & \multicolumn{5}{|c|}{ Chick characteristics } \\
\hline & & $\begin{array}{l}\text { Chick sex } \\
\text { (F/M) }\end{array}$ & $\begin{array}{l}\text { Chick } \\
\text { lengths } \\
\text { (cm) }\end{array}$ & $\begin{array}{c}\text { Body } \\
\text { temp. }\left({ }^{\circ} \mathrm{C}\right)\end{array}$ & $\begin{array}{c}\text { Culled } \\
\text { Chicks } \\
(\%)\end{array}$ & $\begin{array}{c}\text { Chick } \\
\text { quality } \\
(\%)\end{array}$ \\
\hline \multirow{5}{*}{ Egg shell pigmentation } & LP & 1.17 & $16.34^{b}$ & 39.63 & 2.22 & $91.03^{b}$ \\
\hline & MP & 1.36 & $17.24^{\mathrm{ab}}$ & 40.06 & 1.87 & $92.13^{a b}$ \\
\hline & HP & 1.33 & $17.58^{\mathrm{a}}$ & 39.74 & 1.49 & $93.17^{\mathrm{a}}$ \\
\hline & SE & 0.31 & 0.84 & 0.55 & 1.43 & 1.12 \\
\hline & $P$ value & 0.5524 & 0.0582 & 0.4040 & 0.6864 & 0.0750 \\
\hline \multirow{4}{*}{ Lighting conditions } & $\mathbf{D}$ & 1.35 & 16.87 & 39.74 & 2.23 & 91.39 \\
\hline & PS & 1.21 & 17.24 & 39.88 & 1.48 & 92.69 \\
\hline & SE & 0.31 & 0.97 & 0.56 & 1.36 & 1.48 \\
\hline & $P$ value & 0.3492 & 0.4335 & 0.5881 & 0.2585 & 0.0810 \\
\hline \multirow{8}{*}{$\begin{array}{c}\text { Pigmentation X } \\
\text { Lighting interactions }\end{array}$} & LP X D & 1.17 & 16.40 & 39.61 & 2.97 & $90.50^{b}$ \\
\hline & MP X D & 1.33 & 16.72 & 39.93 & 2.26 & $91.35^{\mathrm{ab}}$ \\
\hline & HP X D & 1.55 & 17.49 & 39.68 & 1.48 & $92.32^{\mathrm{ab}}$ \\
\hline & LP XPS & 1.17 & 16.28 & 39.66 & 1.47 & $91.55^{a b}$ \\
\hline & MPXPS & 1.38 & 17.76 & 40.19 & 1.48 & $92.71^{a b}$ \\
\hline & HP XPS & 1.01 & 17.67 & 39.80 & 1.50 & $93.81^{\mathrm{a}}$ \\
\hline & SE & 0.31 & 0.86 & 0.61 & 1.48 & 1.27 \\
\hline & $\mathrm{P}$ value & 0.4546 & 0.1947 & 0.8476 & 0.7485 & 0.0150 \\
\hline
\end{tabular}

Superscripts $^{\mathrm{a} \text { and } \mathrm{b}}$ in a row mean that the common $(\mathrm{P} \leq 0.05)$ is significantly different.

Pigmentation level: Low (LP), Medium (MP), Heavy (HP). Lighting conditions: Dark (D), Light pulses (PS)

Chick's performance:

Chick weight gain:

Results of chick weight gain (Table 4) show no differences in weight gain traits of chicks produced from egg shell pigmentation groups. In light pulses treatment, chick weight at sevenday old chicks and their relative weight gain percentages were significantly heavier in groups of eggs subjected to light pulses than eggs incubated under dark conditions due to light acceleration. There was a 
significant interaction between light pulses and shell pigmentation groups in chick weight at seven day and relative weight gain. Chick weight loss and relative weight gain percentages of medium egg shell pigmentation subjected to pulsed light had higher values.

Table 4. Chick weight and gain as affected by light pulses and shell pigmentation

\begin{tabular}{|c|c|c|c|c|c|c|}
\hline \multirow{2}{*}{\multicolumn{2}{|c|}{ Treatments }} & \multicolumn{5}{|c|}{ Chick weight gain (CWG, g) } \\
\hline & & $\begin{array}{l}\text { CW at } \\
\text { hatch }\end{array}$ & CW at pull & $\begin{array}{c}\text { CW loss } \\
\%\end{array}$ & $\begin{array}{c}\text { 7day-old } \\
\text { CW }\end{array}$ & $\begin{array}{c}\text { Relative WG, } \\
\%\end{array}$ \\
\hline \multirow{5}{*}{$\begin{array}{c}\text { Egg shell } \\
\text { pigmentation }\end{array}$} & LP & 35.07 & 33.32 & 5.00 & 88.01 & 62.11 \\
\hline & MP & 35.62 & 33.65 & 5.52 & 90.93 & 62.97 \\
\hline & HP & 35.75 & 33.90 & 5.15 & 90.97 & 62.72 \\
\hline & SE & 1.89 & 1.77 & 0.71 & 5.27 & 1.10 \\
\hline & $P$ value & 0.6973 & 0.7655 & 0.2594 & 0.3667 & 0.1958 \\
\hline \multirow{4}{*}{ Lighting conditions } & $\mathrm{D}$ & 34.89 & 33.15 & 4.97 & $87.19^{b}$ & $61.97^{b}$ \\
\hline & PS & 36.06 & 34.09 & 5.47 & $92.75^{\mathrm{a}}$ & $63.23^{\mathrm{a}}$ \\
\hline & SE & 1.77 & 1.68 & 0.68 & 4.53 & 0.89 \\
\hline & $\mathrm{P}$ value & 0.0800 & 0.1386 & 0.0521 & 0.0023 & 0.0006 \\
\hline \multirow{8}{*}{$\begin{array}{c}\text { Pigmentation X } \\
\text { Lighting } \\
\text { interactions }\end{array}$} & LP X D & 34.41 & 32.70 & $5.00^{\mathrm{ab}}$ & $85.12^{\mathrm{c}}$ & $61.58^{\mathrm{c}}$ \\
\hline & MP X D & 35.03 & 33.21 & $5.17^{\mathrm{ab}}$ & $87.60^{\mathrm{bc}}$ & $62.08^{b c}$ \\
\hline & HP X D & 35.22 & 33.55 & $4.74^{b}$ & $88.84^{\mathrm{abc}}$ & $62.24^{\mathrm{bc}}$ \\
\hline & LP X P & 35.72 & 33.94 & $4.99^{\mathrm{ab}}$ & $90.89^{\mathrm{abc}}$ & $62.64^{b c}$ \\
\hline & MP X P & 36.20 & 34.08 & $5.86^{\mathrm{a}}$ & $94.26^{\mathrm{a}}$ & $63.85^{\mathrm{a}}$ \\
\hline & HP X P & 36.27 & 34.25 & $5.56^{\mathrm{ab}}$ & $93.09^{\mathrm{ab}}$ & $63.20^{\mathrm{ab}}$ \\
\hline & $\mathrm{SE}$ & 1.89 & 1.79 & 0.66 & 4.61 & 0.85 \\
\hline & $\mathrm{P}$ value & 0.6048 & 0.7450 & 0.0207 & 0.0398 & 0.0040 \\
\hline
\end{tabular}

Superscripts ${ }^{\mathrm{a}}$ and $\mathrm{c}$ in a row mean that the common $(\mathrm{P} \leq 0.05)$ is significantly different.

Pigmentation level: Low (LP), Medium (MP), Heavy (HP). Lighting conditions: Dark (D), Light pulses (PS)

A positive correlation occurs between chick weight and subsequent performance of adult weight. Halevy et al. (2006) found that lighting stimuli increased hatch chick muscle develop and growth by enhancing in satellite cells number. They found that the light stimulatory on the growth of post-hatch muscle is result of increased proliferating and differentiating of synchronization in adult myoblasts and myofiber. The obtained results of the present study are in partial agreement with those of Abd ElAzim et al. (2005), Khalil (2009) and Farghly et al. (2015\&2017a) who reported that eggs exposed to light during incubation improved the chick weight gain compared to those incubated in darkness. Ozkan et al. (2012b) indicated that incubation under light increased weight gain and breast muscle weights of broilers. Enhance the post-hatching performance of chick has been reported by passing of light into the incubators environment (Shafey et al., 2002; Shafey et al., 2004, Shafey et al., 2005 and Shafey et al., 2007). Farghly (2015) reported that hatch chick weight, 7-day-old chick weights and relative weight gains were significantly $(\mathrm{P} \leq 0.05)$ increased due to expose the incubated eggs to pulsed light. On the other hand, Archer et al. (2009) reported that incubated light did not affect any productive parameters in broiler. Farghly (2012) and Farghly et al. (2015) reported that pulsed light did not affect hatch chick and hatch weight loss. Farghly (2015) revealed that pulsed light did not affect chick weight loss. Rozenboim et al. (2004), Halevyet al. (2006) and Zhang et al. (2012) noted positive effects of incubated light on 0 - to 6 -d weight gain and breast weight

Since egg shell pigmentation did not have marked effects on embryo development (Table 1) therefor there was no differences in chick weight. Farghlyet al. (2015) found that chick weight was significantly heavier in the spotted brown egg incubated under dark or light conditions (7.94 and $7.96 \mathrm{~g}$, respectively) than the other groups of eggs, and that chick weight loss, chick sex and chick quality were not affected by egg shell colours. They added that body weight gain was affected by egg shell colours and incubated light, and that chicks of brown eggs presented higher values of body weight gain.

Internal organs and residual yolk sac weight:

The achieved results of the internal organs percentages and residual yolk sac weight are presented in Table (5). No significant differences were found for all internal organs weights and residual yolk sac of shell pigment treatments except liver weight change (highest value for heavy shell pigmentation). Regarding the incubated eggs exposed to pulsed light, chicks produced from these eggs had higher breast, liver and ovary percentage changes in weight. However, insignificant differences were observed in relative weights of the residual yolk sac, legs, heart and testis. Eggs with medium and heavy pigmentation that were subjected to pulsed light had the highest changes in breast and liver weight. Ozkan et al. (2012b) found that groups of eggs subjected to pulsed light had higher breast weights with no affect other traits measured. Zhanget al. (2012) reported 
thatbreast muscle percentage change in weight in the light exposed egg group was significantly increased compared with eggs in darkness groups.

Table 5. The relative organs weight as affected by light pulses and shell pigmentation

\begin{tabular}{|c|c|c|c|c|c|c|c|c|}
\hline \multirow{2}{*}{\multicolumn{2}{|c|}{ Treatments }} & \multicolumn{7}{|c|}{ Chick internal organs (\%) } \\
\hline & & \multirow{2}{*}{$\begin{array}{c}\begin{array}{c}\text { Residua } \\
\text { l yolk } \\
\text { sac }\end{array} \\
5.24 \\
\end{array}$} & \multirow{2}{*}{$\begin{array}{c}\text { Breast } \\
3.09\end{array}$} & \multirow{2}{*}{$\begin{array}{l}\text { Legs } \\
4.08\end{array}$} & \multirow{2}{*}{$\begin{array}{l}\text { Liver } \\
2.69^{b}\end{array}$} & \multirow{2}{*}{$\begin{array}{r}\text { Heart } \\
0.67\end{array}$} & \multirow{2}{*}{$\begin{array}{r}\text { Ovary } \\
0.139\end{array}$} & \multirow{2}{*}{$\begin{array}{r}\text { Tests } \\
\mathbf{0 . 0 2 9}\end{array}$} \\
\hline \multirow{5}{*}{$\begin{array}{c}\text { Egg shell } \\
\text { pigmentation }\end{array}$} & LP & & & & & & & \\
\hline & MP & 5.17 & 3.19 & 4.08 & $2.78^{\mathrm{ab}}$ & 0.67 & 0.148 & 0.036 \\
\hline & HP & 5.16 & 3.25 & 4.21 & $2.88^{\mathrm{a}}$ & 0.71 & 0.152 & $\mathbf{0 . 0 3 7}$ \\
\hline & SE & 0.36 & 0.35 & 0.33 & 0.19 & 0.12 & 0.03 & 0.009 \\
\hline & $\mathrm{P}$ value & 0.8521 & 0.5896 & 0.5786 & 0.0927 & 0.7029 & 0.6750 & 0.1585 \\
\hline \multirow{4}{*}{$\begin{array}{c}\text { Lighting } \\
\text { conditions }\end{array}$} & D & 5.26 & $3.02^{b}$ & 4.05 & $2.69^{b}$ & 0.65 & $0.135^{b}$ & 0.032 \\
\hline & PS & 5.13 & $3.34^{\mathrm{a}}$ & 4.20 & $2.88^{\mathrm{a}}$ & 0.71 & $0.158^{\mathrm{a}}$ & 0.036 \\
\hline & SE & 0.35 & 0.29 & 0.32 & 0.18 & 0.18 & 0.03 & 0.009 \\
\hline & $\mathrm{P}$ value & 0.3168 & 0.0053 & 0.2150 & 0.0078 & 0.1879 & 0.0483 & 0.3673 \\
\hline \multirow{8}{*}{$\begin{array}{c}\text { Pigmentation } \\
\text { X Lighting } \\
\text { interactions }\end{array}$} & LP X D & 5.25 & $2.91^{b}$ & 4.11 & $2.60^{b}$ & 0.64 & 0.130 & 0.029 \\
\hline & MP X D & 5.27 & $3.00^{\mathrm{ab}}$ & 3.93 & $2.62^{b}$ & 0.64 & 0.128 & 0.032 \\
\hline & HP X D & 5.25 & $3.13^{\mathrm{ab}}$ & 4.12 & $2.85^{\mathrm{a}}$ & 0.69 & 0.146 & $\mathbf{0 . 0 3 7}$ \\
\hline & LP X P & 5.24 & $3.27^{\mathrm{ab}}$ & 4.05 & $2.78^{\mathrm{ab}}$ & 0.69 & 0.148 & 0.030 \\
\hline & MP X P & 5.07 & $3.38^{\mathrm{a}}$ & 4.23 & $2.94^{\mathrm{a}}$ & 0.71 & 0.168 & 0.040 \\
\hline & HP X P & 5.07 & $3.37^{\mathrm{a}}$ & 4.31 & $2.92^{\mathrm{a}}$ & 0.73 & 0.158 & $\mathbf{0 . 0 3 7}$ \\
\hline & $\mathrm{SE}$ & 0.37 & 0.31 & 0.33 & 0.16 & 0.13 & 0.03 & 0.009 \\
\hline & $\mathrm{P}$ value & 0.8911 & 0.1155 & 0.5278 & 0.0083 & 0.7946 & 0.3524 & 0.3611 \\
\hline
\end{tabular}

Superscripts $^{\mathrm{a} \text { and } \mathrm{b}}$ in a row mean that the common $(\mathrm{P} \leq 0.05)$ is significantly different.

Pigmentation level: Low (LP), Medium (MP), Heavy (HP). Lighting conditions: Dark (D), Light pulses (PS).

Light pulses did not effect on yolk free chick weight, which is an indicator of chick development. All yolk sac is entered into the abdomen on the $19^{\text {th }}$ day of incubation, and the drawn yolk residue is placed or located within the cavity at the last of $20^{\text {th }}$ day of incubation period. At hatching, about 30 percent of the origin nutrients in yolk are exist in yolk residues, and nutrients function as a main energy source for hatchling during the first three days of life. Gous (2010) stated that yolk sac utilization can be one of the limiting factors that restrict embryonic growth. Yolk sac membrane weight has influenced yolk nutrient utilization, which would result in higher yolk absorption. Ozkan et al. (2012a) found that light exposure during incubation decreased residual yolk, while had no affect chick weight, heart and liver percentages. Rozenboim et al. (2004) reported that higher embryo weight in $21 \mathrm{~d}$ of embryo age was accompanied by low residual yolk percent at d18, which may be attributed to a more efficient yolk use or consumption, as well as more improve or increase in breast weight of broiler embryos with illumination during incubation period. The current data show that pigment level did not effect on hatch chick organs. These may be concluded that breast and liver percentages of embryos subjected to incubated pulsed light are influenced by the extent of the pigmentation. Eggs with heavily pigmented brown shells were more affected by light pulses than other shades of brown eggs. The previous findings appeared the importance role in defining eggshells characteristics and the potential of light exposure during incubation period on pre and post hatch performance. The light level of egg shell pigmentation may have allowed or passed more lighting, above optimum intensity to reaching the embryos and that light-filtering action of shell pigment in the heavy eggshell pigmentation level tended to decrease its effect. Farghly (2015) found that chick organs and residual yolk sac percent were affected by incubation light pulses and that chicks produced from eggs subjected to pulsed light had higher breast, liver and ovary percentages in weight changes, while no differences were observed in residual yolk sac percent.

\section{CONCLUSION}

It could be concluded that exposing medium or heavy pigmented eggs of Rhode Island Red chicken to pulsed light during the incubation period increase each of embryonic and hatchling performance. Optimum incubation conditions lead to maximum hatchability of healthy hatchlings. Therefore, it could be recommended that pulsed light could be applied on either medium or heavy pigmented eggs to have a high hatchability and also reducing hatch losses with insignificant negative effects on chick quality score.

\section{REFERENCES}

Abd El-Azim A., Arram G., Hataba N., and M. Abd ElSamad, 2005. Effect of temperature and/or light during incubation on: 1-embryonic development and hatchability in Fayoumi and Golden Montazah chickens. Paper presented at the 3rd 
International Poultry Conference, 4-7 Apr., 2005, Hurghada-Egypt.

Abiola, S., Meshioye O., Oyerinde and B. M. Bamgbose, 2008. Effect of egg size on hatchability of broiler chicks. Arch. Zootec, 57: 83-86.

Archer, 2015. Timing of light exposure during incubation to improve hatchability, chick quality and post-hatch well-being in broiler chickens: 21 or 18 days. International Journal of Poultry Science, 14(5): 293.

Archer, G., and J. Mench, 2014. The effects of the duration and onset of light stimulation during incubation on the behavior, plasma melatonin levels, and productivity of broiler chickens. Journal of animal science, 92 (4): 1753-1758.

Archer, G., Shivaprasad H., and J. Mench, 2009. Effect of providing light during incubation on the health, productivity, and behavior of broiler chickens. Poultry science, 88(1): 29-37.

Avila, R., Samar M., Juri H., Femopase G., Hidalgo M., Ferrero J. and G. Juri, 2009. Biological Effects Produced by Intense Pulsed Light (Xe-Cl) on the Cartilage of the Tongue Chick Embryo Using Various Filters. Int. Journal Morphol, 27(4): 1003-1008.

Chukwuka, O., Okoli I., Okeudo N., Udedibie A., Ogbuewu, I., Aladi N. and A. Omede, 2011. Egg quality defects in poultry management and food safety. Asian Journal of Agricultural Research, 5(1): 1-16.

Clifford, J., and G. Philpott, 2002. Light and sound. The Longman Physics, 32-46.

Copur, G., Baylan M., and S. Canogullari, 2010. Egg weight but not egg shape index, determines the hatchability in Japanese quail (Coturnix coturnix japonica). Journal Anim. Vet. Adv, 9: 1890-1895.

Csernus, V. J., Nagy A. D., and N. Faluhelyi, 2007. Development of the rhythmic melatonin secretion in the embryonic chicken pineal gland. General and comparative endocrinology, 152(2): 148-153.

Deeming, D. C. 1995. What is chick quality? World's Poult. Sci. Journal 11:20-23.

Deeming, C. D. 2011. A review of the relationship between eggshell colour and water vapour conductance. Avian Biology Research, 4(4): 224230.

Duncan, D.B., 1955. Multiple range and multiple tests. Biometrics, 11: 1-42.

Fairchild, B., and V. Christensen, 2000. Photostimulation of turkey eggs accelerates hatching times without affecting hatchability, liver or heart growth, or glycogen content. Poultry science, 79(11): 1627-1631.

Faluhelyi, N., and V. Csernus, 2007. The effects of environmental illumination on the in vitro melatonin secretion from the embryonic and adult chicken pineal gland. General and comparative endocrinology, 152(2), 154-158.

Farghly, M. 2012. Effect of light pulses during incubation on hatch performance in different eggs size of Japanese quail. Paper presented at the $3 \mathrm{rd}$
Mediterranean Poultry Summit and 6 th International Poultry Conference, 26-29 March 2012, Porto-Marina, Alexandria, Egypt.

Farghly, M. 2015. Using light flashes as environmental stimulator for embryonic growth and hatch performance of Rhode Island red chicken eggs. Egyptian Poultry Science Journal, 35(1): $245-261$.

Farghly, M., Mahrose K., and D. Abou-Kassem, 2015. Pre and post hatch Perfomance of different Japanese Quail Egg Colors Incubated under Photostimulation. 9(1): 19 -30.

Farghly, M., and K. M. Mahrose, 2012. Effects of light during storage and incubation periods on pre and post hatch performance of Japanese quail. Egyptian Journal of Poultry Sci, 32, 947-958.

Farghly M. F. A. and M. E. Ghonime, 2016. Effect of light intensity during incubation period on hatch performance in different eggs size of dandarawi chicken. Third International Conference on Agricultural Biotechnology Applications, April 59, 2016, Moshtohor and Sharm El-Sheikh, Egypt.

Farghly M. F. A. and M. Shabaan, 2016. Hatch performance in different eggs color of Rhode Island Red chicken eggs as affected by incubated light intensity. Third International Conference on Agricultural Biotechnology Applications, April 59, 2016, Moshtohor and Sharm El-Sheikh, Egypt.

Farghly M. F. A., M. A. Metwally, M. I. ElKelawyand Hoda R. Hassan, 2017a. Effect of lighting during incubation period on hatch performance in different eggs size of Japanese quail. The 16th Scientific Conference of Animal Nutrition, 28 November to 1 December 2017, Luxor, Egypt (Abstract).

Farghly M. F. A., M. G. Abdelfatah, M. A. Abdelnabi and M. Shabaan,2017b. Effect of incubated light intensity on pre and post hatch performance in different eggs size of Japanese quail. The 16th Scientific Conference of Animal Nutrition, 28 November to 1 December 2017 , Luxor, Egypt (Abstract).

Ghatpande, A., Ghatpande, S., and M. Khan, 1994. Effect of different intensities of fluorescent light on the early development of chick embryos in ovo. Cellular and molecular biology research, 41(6): 613-621.

Gous, R. 2010. Nutritional limitations on growth and development in poultry. Livestock Science, 130(1): 25-32.

Halevy, O., Piestun, Y., Rozenboim, I., and Z.Yablonka-Reuveni, 2006. In ovo exposure to monochromatic green light promotes skeletal muscle cell proliferation and affects myofiber growth in posthatch chicks. American Journal of Physiology-Regulatory, Integrative and Comparative Physiology, 290(4): R1062-R1070.

Hill, W. L., Bassi K. L., Bonaventura, L., and J. E. Sacus, 2004. Prehatch entrainment of circadian rhythms in the domestic chick using different light regimes. Developmental psychobiology, 45(3): 174-186. 
Khalil, H. 2009. Productive and physiological responses of Japanese quail embryos to light regime during incubation period. Slovak Journal of Animal Science, 42 (2): 79, 86.

Kumar, A., Das, K., Mukherjee, K., Bharti, A., and A. Singh, 2012. Frequency of different shell color and its effect on the fertility and hatchability in Black rock, Gramapriya and Vanaraja breeds of chicken. Veterinary World, 5 (10).

Lasagabaster, A., Arboleya, J. C., and I. M. De Maranon, 2011. Pulsed light technology for surface decontamination of eggs: impact on Salmonella inactivation and egg quality. Innovative Food Science \& Emerging Technologies, 12(2): 124-128.

Manzocco, L., Maifreni, M., Anese, M., Munari, M., Bartolomeoli, I., Zanardi, S.,and M. C. Nicoli, 2014. Effect of pulsed light on safety and quality of fresh egg pasta. Food and Bioprocess Technology, 7(7): 1973-1980.

Özkan, S., Yalçın, S., Babacanoğlu, E., Kozanoğlu, H., Karadaş, F., and S. Uysal, 2012a. Photoperiodic lighting (16 hours of light: 8 hours of dark) programs during incubation: 1. Effects on growth and circadian physiological traits of embryos and early stress response of broiler chickens. Poultry science, 91(11): 2912-2921.

Özkan, S., Yalçın, S., Babacanoğlu, E., Uysal, S., Karadaş, F., and H. Kozanoğlu, 2012 b. Photoperiodic lighting (16 hours of light: 8 hours of dark) programs during incubation: 2. Effects on early posthatching growth, blood physiology, and production performance in broiler chickens in relation to posthatching lighting programs. Poultry science, 91(11): 2922-2930.

Pandian, C., Omprakash, A., Selvan, S., and A. Sundaresan, 2015. Effect of pulsed electro magnetic field (pemf) exposure on hatchability performance of Japanese quail hatching eggs. Indian Journal of Veterinary Sciences \& Biotechnology, 11(1).

Portugal, S., Hauber, M., Maurer, G., Stokke, B., Grim, T., and P. Cassey, 2014. Rapid development of brood - parasitic cuckoo embryos cannot be explained by increased gas exchange through the eggshell. Journal of Zoology, 293(4): 219-226.

Rozenboim, I., Piestun, Y., Mobarkey, N., Barak, M., Hoyzman, A., and O. Halevy, 2004. Monochromatic light stimuli during embryogenesis enhance embryo development and posthatch growth. Poultry science, 83(8): 14131419.

SAS. 2009. SAS User's Guide. Statistics. Version 9.1 ed. SAS Institute Inc., Cary, NC. USA.
Shafey, T., Al-Batshan, H., and M. Ghannam, 2007. Effects of electrical field on hatchability performance of eggs from a layer-type breeder. British poultry science, 48(2): 145-153.

Shafey, T., Al-Batshan, H., Ghannam, M., and M. Al-Ayed, 2005. Effect of intensity of eggshell pigment and illuminated incubation on hatchability of brown eggs. British poultry science, 46(2): 190-198.

Shafey, T., Al-Mohsen, T., Al-Sobayel, A., AlHassan, M., and M. Ghnnam, 2002. Effects of eggshell pigmentation and egg size on the spectral properties and characteristics of eggshell of meat and layer breeder eggs. Asian Australasian Journal of Animal Sciences, 15(2): 297-302.

Shafey, T., Ghannam, M., Al-Batshan, H., and M. Al-Ayed, 2004. Effect of pigment intensity and region of eggshell on the spectral transmission of light that passes the eggshell of chickens. International Journal of Poultry Science, 3(3): 228-233.

Shanawany, M. 1990. Acceleration of embryonic development and hatching time by photoperiod stimulation. Archiv für Geflügelkunde, 54(5): 187-189.

Town, G., Ash, C., Eadie, E., and H. Moseley, 2007. Measuring key parameters of intense pulsed light (IPL) devices. Journal of Cosmetic and Laser Therapy, 9(3): 148-160.

Yang, H., Wang, Z., and J. Lu, 2009. Study on the relationship between eggshell colors and egg quality as well as shell ultrastructure in Yangzhou chicken. African Journal of Biotechnology, 8(12): 2898.

Yu, Y., Li, Z., and J. Pan, 2016. Changes in pigment, spectral transmission and element content of pink chicken eggshells with different pigment intensity during incubation. PeerJ, 4, e1825.

Yu, Y., Wang, Z., Cao, J., Dong, Y., Wang, T., and Y. Chen, 2014. Effects of monochromatic light stimuli on the development and Muc2 expression of goblet cells in broiler small intestines during embryogenesis. Poultry science, 93(7): 18011808.

Zhang, L., Zhang, H., Qiao, X., Yue, H., Wu, S., Yao, J., and G. Qi, 2012. Effect of monochromatic light stimuli during embryogenesis on muscular growth, chemical composition, and meat quality of breast muscle in male broilers. Poultry science, 91(4): 1026-1031. 
تحسين ألاداء الجنينـى و الفقس لبيض دجـاج الرود ايلاند الأحمر المعرض للنبضـات الضوئية اثثـاء التفريخ وعلاقتهـا بصبغة القشرة

محمد فرغلى علم الدين فرغلى' و اسامة حسن منصور الجارحى' ومصطفى جلال عبد الفتاح' 1 ـ قسم إنتاج الدواجن، كلية الزراعة، جامعة اسيوط، مصر، - قسم إلانتاج الحيوانى، كلية الزرراعة، جامعة بنها، مصر

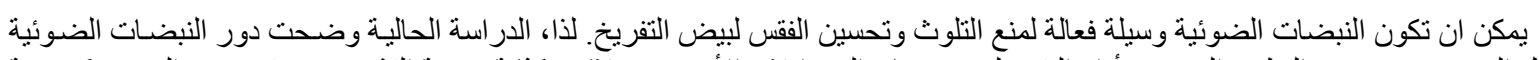

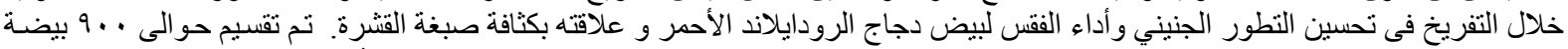

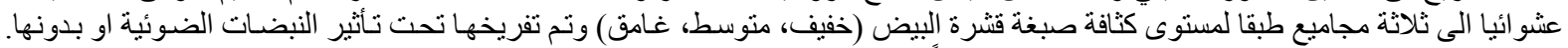

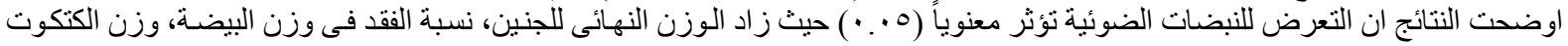

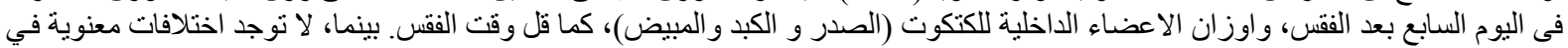

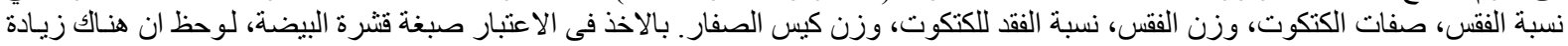

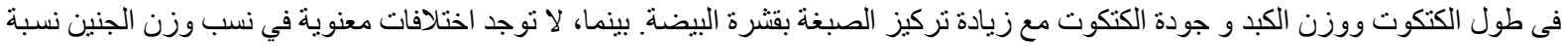

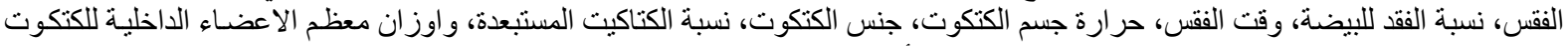

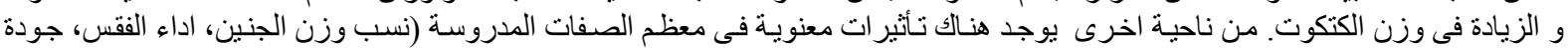

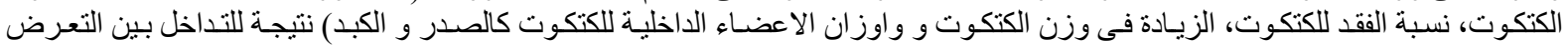

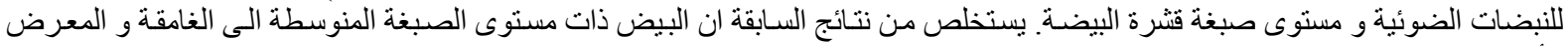

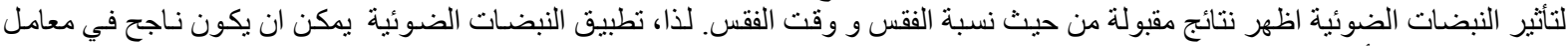
التفريخ بذون اي تأثيرات سلبية على جودة الكنكوت. 